\title{
ANÁLISE SOCIOSSEMIÓTICA DO DISCURSO POLÍTICO-PARTIDÁRIO
}

\author{
Socio semiotics analysis of a discourse of a political party
}

\section{Análisis socio semiótica del discurso de un partido político}

\author{
Rosália Maria Netto Prados ${ }^{1}$ \\ Moacir $\mathrm{Wuo}^{2}$ \\ Luci Mendes de Melo Bonini ${ }^{3}$
}

\section{Resumo}

Propõe-se identificar, descrever e analisar a estrutura narrativa de um discurso político partidário, no editorial de uma publicação periódica de um partido político brasileiro, surgido nos anos 80. O objeto de estudo é o editorial na página 2 da edição número 15 da revista Pensar Verde, uma publicação patrocinada pela Fundação Verde Herbet Daniel, ligada ao Partido Verde. Esta revista encontra-se numa plataforma de aceso aberto para publicação de livros e revistas intitulada ISSU. É um estudo do discurso, cuja metodologia baseia-se na Semiótica, mais especificamente na Sociossemiótica, pois trata-se de um estudo de discursos sociais, cujos sujeitos enunciador e enunciatário são coletivos, ou grupos sociais, ou partidos políticos.

Palavras-chave: discurso político, sociossemiótica, partido político.

\begin{abstract}
${ }^{1}$ Licenciada em Letras e pedagogia, Doutora em Semiótica e Linguística Geral, pela USP, pós-doutora em Ciências da Comunicação, pela ECA-USP. Membro do Corpo Editorial das Revistas Acta Semiótica e Revista Brasileira de Linguística. Docente pesquisadora do Mestrado em Políticas Públicas da Universidade de Mogi das Cruzes e professora da FATEC-SP. Políticas Culturais e Educação: estudo dos discursos, multiculturalismo e diversidade. E-mail: rosalia.prados@gmail.com

${ }^{2}$ Licenciado em Ciências Biológicas e Pedagogia, Mestre em Psicologia Escolar e Doutor em Psicologia pela PUC-CAMP. Coordenador do Curso de Biologia e docente pesquisador do Mestrado em Políticas Públicas da Universidade de Mogi das Cruzes, Coordenador do PIBID-CAPES, na mesma instituição e coordenador do projeto de Pesquisa: BIODAT - Biodiversidade do Alto Tietê. E-mail: moacir@umc.br

${ }^{3}$ Doutora e Mestre em Comunicação e Semiótica pela PUC-SP, coordenadora do Núcleo de Pesquisa em Ciências Sociais Aplicadas (NCSA) da Universidade de Mogi das Cruzes e Líder do GRUPPU - Grupo de Pesquisa em Políticas Públicas - CNPq, coordenadora do Mestrado em Políticas Públicas da Universidade de Mogi das Cruzes. Membro do conselho editorial da revista Acta Semiótica (UFPB) e da Revista Nexi (PUC-SP) e revisora de outros periódicos de circulação nacional. Responsável pelo projeto de pesquisa: Observatório Cultural do Alto Tietê. E-mail: lucibonini@gmail.com
\end{abstract}


This paper intends to identify, describe and analyze the narrative structure of a partisan political speech a magazine of a Brazilian political party that emerged in the 80 s. The subject of this research is the editorial on page 2 of the 15th edition of the magazine Pense Verde (Think Green), a publication sponsored by Herbet Daniel Green Foundation, linked to the Green Party. This magazine is an open access platform for publication of books and magazines entitled ISSU. This is a study of discourse, whose methodology is based on semiotics, specifically in Socio semiotics because it is a study of social discourses, whose enunciating subject and enunciatee are collective, or social groups, or political parties.

Keywords: politics discourse, socio semiotics, politics party.

\section{Resumen}

Este trabajo se propone identificar, describir y analizar la estructura narrativa de un discurso político partidista una revista de un partido político brasileño que surgió en los años 80. El objeto de esta investigación es el editorial en la página 2 de la $15^{\text {a }}$ edición de la revista Pense Verde (Piensa Verde), una publicación patrocinada por Fundación Verde Herbet Daniel, vinculada al Partido Verde. Esta revista es una plataforma de acceso abierto a la publicación de libros y revistas con derecho ISSU. Se trata de un estudio del discurso, cuya metodología se basa en la semiótica, específicamente en la semiótica Socio porque es un estudio de los discursos sociales, cuya enunciación y sujeto enunciatário son colectivos o grupos sociales o partidos políticos.

Palabras-clave: discurso político, socio semiótica, partido político.

\section{INTRODUÇÃO}

No discurso político, podem se manifestar temas organizados a partir de diferentes contextos que, por sua vez, possibilitam várias leituras. Apresentam-se, neste estudo, aspectos da interdiscursividade e da intertextualidade a partir de uma proposta de análise do discurso de uma propaganda político-partidária expressa numa revista digital de um partido político.

Hoje, nos discursos midiáticos e políticos, é possível identificar valores que vêm expressos em diferentes textos sobre sustentabilidade e meio ambiente, que se apresentam nas práticas sociais contemporâneas e que não existiam no jornalismo, nem estavam presentes nos discursos políticos, no século passado, na década de 1950, por exemplo. A mídia reflete os temas mais debatidos na política, em específico a mídia brasileira passou a debater mais fatos 
e dados sobre o meio ambiente e suas questões depois da conferência conhecida como ECO92, que aconteceu no Rio de Janeiro.

Valores como reforma agrária, preservação, conservação e salvaguarda de bens ambientais são, cada vez mais, debatidos nas universidades como temas de pesquisa, e rapidamente se transformaram em elementos de propulsão para a mídia e sua apropriação no senso comum, consequentemente, desperta, nos candidatos, elementos subjacentes de discursos eleitoriais, marketing político e planos de governos.

São objetivos deste trabalho: identificar, descrever e analisar as relações entre destinadores e destinatários, sujeitos e objetos de valor, percursos dos sujeitos, ou seja, a estrutura narrativa do discurso político manifestado no texto do editorial, da edição de número 15, da revista Pensar Verde, do Partido Verde. Para isso, a metodologia de análise se fundamenta na Semiótica do discurso, segundo Greimas (2001).

Durante o intervalo entre as disputas eleitorais, a ideologia partidária se manifesta com mais profusão nas páginas da web e redes sociais que divulgam conteúdos relacionados a sua atuação específica, caso que se discute neste estudo. No Brasil, esses discursos que reforçam a ideologia partidária apresentam, por um lado, uma forma de se diferenciar de outros nesses períodos, longe das disputas aos cargos do legislativo e executivo, por outro, acabam se diluindo em coalisões ou coligações quando se aproxima o pleito eleitoral o que enfraquece o poder de decisão dos eleitores.

A Semiótica de linha francesa, protagonizada por Greimas (2001), tem suas bases na Linguística e trata, não só dos signos, mas da significação, a axiologia, a narratividade e a discursividade compõem um percurso. De acordo com esse percurso gerativo do sentido, a descrição das estruturas discursiva, ou superficial, narrativa e semântica profunda dos discursos, é possível a reconstrução do processo discursivo do universo de discurso político, para um estudo das relações de linguagem, como capacidade humana de discursos e suas contradições, e dos processos de construção do saber compartilhado sobre a política-eleitoral.

\section{SOCIOSSEMIÓTICA E DISCURSOS CONTEMPORÂNEOS}

Nessa análise do discurso de propaganda político-partidária, manifestado numa publicação específica de um partido político, são examinadas as tensões em conflito que se estabelecem nas relações sociais entre os sujeitos de tais produções discursivas. Um universo de discurso deve ser visto como processo de produção, enquanto os textos-enunciados são vistos como produto, resultante do percurso gerativo da enunciação. Dessa maneira, segundo 
Prados (2009) evidencia-se que é no discurso que a subjetividade se constrói nesse percurso de geração do sentido.

A Sociossemiótica, segundo Landowski (1992), trata da captura do sentido enquanto dimensão provada do ser no mundo, ou seja, o sentido em situação ou em ato, construído no momento da interação e, além disso, examina, no seio da vida social, o funcionamento desses processos discursivos e seus respectivos sentidos nas práticas sociais. Estuda, portanto, os discursos científico, tecnológico, político, jurídico, jornalístico, publicitário, pedagógico, burocrático, religioso, dentre outros. São discursos que se caracterizam por enunciador e enunciatário coletivos, ou seja, um grupo ou segmento social, como um partido político, ou legisladores, ou ainda uma comunidade científica, etc.

O discurso, segundo a perspectiva sociossemiótica, portanto, é considerado como resultado de uma expressão humana em que se reproduzem representações e experiências. Mas ainda é necessário delimitar elementos que são característicos da análise de discurso, na qual se baseiam as ideias de Fontanille (2008). Trata-se de uma tendência teórica de análise do discurso por meio da desconstrução de suas estruturas, de acordo com a metodologia semiótica, pois a existência das coisas somente faz sentido por meio da produção de um discurso que lhes atribui significados, ou seja, o discurso produz sentido.

Dessa maneira os processos culturais são apreendidos no convívio social, uma vez que, as linguagens verbal, não-verbais e sincréticas são particulares, de acordo com o contexto sociocultural. Os diferentes tipos de textos são produtos de universos discursivos construídos pelos sujeitos nas suas práticas sociais e seus respectivos processos de produção de sentidos.

Para Landowski (1992), a Sociossemiótica trata, não só do exame da terminologia e das figuras através das quais se exprime a diversidade das posições sociais e dos interesses em jogo no discurso, mas também da questão do funcionamento global e da eficácia social dessa atividade discursiva enquanto tal. No estudo dos discursos de propaganda político-eleitorais, somente critério temático da semântica não é suficiente para o respectivo estudo.

(...) o caráter político de um discurso, oral ou escrito, não poderia ater-se apenas, nem mesmo prioritariamente, ao fato de que ele "fala de política" (critério semântico), mas depende muito mais ao fato de que, ao fazê-lo, realiza certos tipos de atos sociais transformadores das relações intersubjetivas (critérios sintáxico e pragmático), estabelece sujeitos "autorizados" (com "direito à palavra"), instala "deveres", cria "expectativas", instaura a "confiança", $e$ assim por diante. (LANDOWSKI, 1992:10)

Assim, na metodologia sociossemiótica, considera-se o sujeito coletivo de determinado discurso, o de propaganda político-partidário. $\mathrm{O}$ sujeito coletivo está indefinidamente em construção, uma vez que, segundo Landowski (1992: 23), a alteridade do 
Outro é um dos elementos da identidade do Nós. Dessa maneira, o discurso político se ancora numa conjuntura que impõe mudanças, apoiado em uma vontade política, gerada, por sua vez num processo discursivo, por um determinado grupo social, um partido.

São pertinentes as considerações sobre a vontade política que move os discursos presentes na mídia, segundo Landowski (1992). Há uma lógica que constitui um dos motivos mais constantes e poderosos da dinâmica do discurso político que é mais profunda e de alcance mais geral, subjacente a todo desejo de renovação, em toda a esperança de ‘transformação do presente' que antes procede do desejo que da vontade ou da necessidade.

Nos discursos de propaganda político-eleitorais caracteriza-se um sujeito político, é evidente, apoiado por movimentos de opinião. Para se compreender a que se deve a força dos movimentos de opinião que apoiam, ou apelam com uma insistência particular para o aparecimento da mudança em política, é necessário considerar que esses movimentos não se detêm somente à racionalidade de um homo politicus ideal, com justos argumentos que o impeliriam a agir para transformar o mundo e torná-lo um mundo melhor, mas sim a "alguma coisa que tem relação com a gestão do sentimento de identidade dos próprios sujeitos, atores ou testemunhos do que muda em torno deles e com eles" (LANDOWSKI, 2002:92).

O desejo de mudança assim, para Landowski, não é apenas uma tomada de posição diante de coisas que mudam, ou que se gostaria que melhorassem, mas também escolher uma maneira determinada de viver seu próprio devir, ou seja, de colocar-se em condição de 'desfrutar o tempo presente', qualquer que seja este, percebendo a si mesmo como imediatamente inscrito no movimento do momento que passa, como participante do desenrolar de uma atualidade vivida em comum com outrem, compartilhada, efetivamente 'presente a si mesmo'. Dessa maneira, a mudança torna-se produtora de identidade construída nos discursos.

Não se trata de, ao aderir à mudança, deixar de ser alguém, ou deixar de apresentar ideias como apresentava antes, mas, segundo Landowski (2002), é talvez exatamente o contrário, um dos meios mais elementares de afirmar sua própria existência, tanto o olhar de si mesmo como diante de outrem. É mudar, se não a vida, em todo o caso, o sentido de sua própria vida.

Segundo a Sociossemiótica, os discursos que circulam na sociedade, como o político, o político-eleitoral, o publicitário, o de propaganda dentre outros, têm seu valor de comunicação atribuído pela sociedade, com seus sujeitos coletivos e esses discursos mantêm entre si redes de relações interdiscursivas e intertextuais. 
Chomsky discute a produção do discurso político, como produtora de opinião. $\mathrm{O}$ autor (2003:14), ao discutir o discurso político, recorre, como exemplo, ao que se diz sobre a necessidade de uma revolução na arte da democracia, que pode ser usada para produzir consenso. Chomsky (2003) trata, neste estudo, do discurso político da democracia progressista. E que, segundo ele, é um discurso que se caracteriza na administração de uma pequena elite, que são aqueles que analisam, executam, tomam decisões e conduzem as coisas no sistema político, econômico e ideológico. "E, do outro lado, há o rebanho assustado, a maioria, espectadora desse processo, mas que, ocasionalmente, lhe é permitido emprestar seu apoio a um ou outro membro da classe especializada" (CHOMSKY, 2003:16).

Segundo Chomsky, acontece assim porque estamos numa democracia e não num estado totalitário (CHOMSKY, 2003:16). Desta maneira, a fabricação do consenso é produto do discurso e é necessária na arte da democracia. Segundo Chomsky, a classe política, nessa análise do discurso de propaganda política, tem de ser suprida de um senso de realidade tolerável, também doutrinada com as convicções convenientes produzidas no contexto social.

Daí a criação de "ilusões necessárias e super-simplificações" (CHOMSKY, 2003:17), emocionalmente eficazes, para conduzir a maioria e que são características dos discursos da propaganda política. Hoje, à medida em que, as sociedades tornam-se mais livres, recorre-se, cada vez mais, às técnicas da propaganda e respectivos discursos.

Na propaganda política, por exemplo, também se percebem essas técnicas de sedução, para o consumo do discurso político. Segundo Baudrillard (1991: 22), o consumo, na qualidade de novo mito tribal, transformou-se na moral do mundo contemporâneo. Vive-se num contexto em que o consumo invade a vida das pessoas, suas relações invadem toda a sociedade e as satisfações pessoais são completamente traçadas através dele. A imagem do candidato é colocada à venda, há uma associação de seu discurso político (programa de governo) a uma estética de discurso político-eleitoral, aos universos simbólicos, que por meio da linguagem verbal e não-verbal, publicidade impressa, vídeos, jingles, uma personalidade (com um estilo de vida, uma postura) é anunciada, convence e envolve (PRADOS, 2006).

\section{MÉTODO}

O percurso metodológico, neste estudo, traça uma abordagem sociossemiótica do discurso, pois considera-se que, a partir do momento em que se escolhe o discurso, como objeto de análise, tem-se a noção de que formas cristalizadas ou convencionais que nele se encontram estão longe de serem unicamente signos. Num discurso são globalmente 
esquematizadas as representações e experiências. Assim, o estudo dos esquemas do discurso toma o lugar do estudo dos signos propriamente ditos (FONTANILLE, 2008).

O objeto de estudo é o editorial na página 2 da edição número 15 da revista Pensar Verde, uma publicação patrocinada pela Fundação Verde Herbet Daniel, ligada ao Partido Verde. Esta revista encontra-se numa plataforma de aceso aberto para publicação de livros e revistas intitulada ISSU.

É um estudo do discurso, cuja metodologia baseia-se na Semiótica, mais especificamente na Sociossemiótica, pois trata-se de um estudo de discursos sociais, cujos sujeitos enunciador e enunciatário são coletivos, ou grupos sociais, ou partidos políticos. São examinadas as tensões em conflito que se estabelecem nas relações entre os sujeitos envolvidos nessas respectivas produções discursivas.

\section{A NARRATIVA DO DISCURSO POLÍTICO-PARTIDÁRIO}

Para Greimas e Fontanille (1993: 12), entre o nível profundo da teorização semântica, ou do sujeito conhecedor e a instância discursiva, que é a do sujeito do fazer, a enunciação é o lugar de mediação, em que se opera a convocação dos universais semióticos, ou linguagens, utilizados em discurso, de acordo com as diferentes formas de embreagem, debreagem e modalização. Mas não é só isso, pois a instância de enunciação concilia, dialeticamente, a geração, isto é, o sentido é gerado, pela convocação dos universais semióticos ou linguagens verbais, não-verbais, e pela gênese, ou seja, pela integração dos produtos da história.

A narrativa dos discursos, portanto, é anterior à sua manifestação, ou melhor, segundo Greimas (2001), a narratividade do discurso pode ser reconhecida em manifestações do sentido aceitando-se a necessidade de uma distinção fundamental entre dois níveis de representação e de análise: um nível aparente da narração, em que as diversas manifestações desta se submetem às exigências específicas das substâncias linguísticas por meio das quais ela se exprime; e um nível imanente, que constitui uma espécie de tronco fundamental comum, em que a narratividade se encontra situada e organizada anteriormente à sua manifestação. Um nível semiótico comum se distingue, portanto, do nível linguístico e lhe é logicamente anterior.

Num discurso, então, há um nível narrativo, que é o da ação, subjacente à enunciação e que pode ser analisado. No desenvolvimento da metodologia semiótica, na etapa narrativa do discurso, atribui-se um status formal ao conceito de actante, que "são os participantes 
implicados em uma ação e que tem nela um papel ativo ou passivo" (CHARAUDEAU e MAINGUENEAU, 2008: 33).

Ainda segundo a análise da narratividade do discurso, descreve-se a transformação, que vai caracterizar a ação. Essa formalização foi necessária, na metodologia semiótica, para a instauração de uma sintaxe narrativa, desloca-se a problemática semântica para a noção de estado. A definição de um ato como 'o que faz ser' permite que se reconheçam dois predicados: fazer x ser (enunciados de ação e enunciados de estado) que constituem uma narrativa mínima: Estado Inicial; Ação / Transformação e Estado final (GREIMAS, 2001).

Os Enunciados de Estado (inicial e final) e Enunciado de Transformação (do Fazer) a partir da relação de Junção - relação entre Sujeito e Objeto de Valor - que pode ser: relação de Conjunção (ter ou conservar o objeto) e relação de Disjunção (não ter alcançado ou conservado o objeto). Esse percurso do Sujeito, de ter/ não ter alcançado/ conservado o Objeto de Valor, é que se caracteriza como Enunciado de Transformação (Prados 2006).

As modalidades simples são as da Competência do sujeito: as virtualizantes (quererfazer, querer-ser, dever-fazer/crer/ser), que definem a instauração do papel actancial Sujeito em relação a um outro papel actancial, o Objeto de Valor; e as atualizantes (poder-fazer, saber-fazer), que definem o desenvolvimento da ação do actante Sujeito. Há, também, no enunciado, as modalidades do Desempenho do Sujeito (fazer / ser). Desta maneira, os discursos apresentam estruturas de poder caracterizadas pela persuasão e sedução e definidas por combinatórias de modalidades, ou sobremodalizações (PAIS, 2005).

Os partidos políticos do sistema partidário brasileiro atual ainda têm dificuldade de construir sua identidade desde o movimento pró-redemocratização, surgido com a promulgação da Constituição Federal em 1988. De acordo com Carreirão e Kinzo (2004) em outros países, este fenômeno vem conduzindo, inclusive, a uma queda do comparecimento eleitoral.

Nesta descrição do discurso político-partidário, segundo essa metodologia, a partir de instaurado um sujeito do querer (e do dever), o discurso, por sua vez, sustenta-se em estruturas de poder e é, também, sobremodalizado. Desta forma, caracteriza-se pelas combinatórias que produzem os efeitos de sentido da persuasão, manipulação, na ordem do saber por provocação ou sedução; ou na ordem do poder, por tentação ou intimidação (BARROS, 1999).

Veja-se o primeiro parágrafo do editorial: 
novas lideranças políticas. Aproveitamos o seminário, Ver de Novo, da Fundação Verde Herbert Daniel com o apoio da Fundação Getúlio Vargas, para revisitar um tema que não está esquecido, mas precisa estar mais presente no ideário verde: a Ecologia Política (PENSAR VERDE, 2015: 2).

Observa-se o destaque para uma edição de fechamento do ano de 2015 e de número 15, ou seja, para o leitor que acompanha ou a lê pela primeira vez, o texto indica que já existem outros números, que é uma publicação em direção ao amadurecimento político, confirmando parcerias com universidades. O discurso de propaganda político-partidária, muito se aproxima do discurso político-eleitoral, pois apresenta combinatórias de modalidades: poder-fazer-querer $\rightarrow$ poder-fazer-saber $\rightarrow$ poder-fazer-dever/crer. Desta maneira, há uma vontade política, que se define por um poder-fazer-querer, para se adquirir um conhecimento (sobre os anseios de um grupo social), definido pelo poder-fazer-saber, a fim de que se instaure um dever, modalidade que caracteriza o discurso da ética e o discurso da lei (o dever de votar), ou um crer, que caracteriza o discurso da sedução (passa-se a acreditar em algo). Acredita-se na mudança, por exemplo. E segundo Landowski (1992), o desejo de mudança constitui-se num processo de identificação dos sujeitos.

Assim, segue o texto com um convite para a mudança, ou descontinuidade do pensamento conservador:

\footnotetext{
Revisitamos o tema, que norteou o primeiro Manifesto do Partido Verde em 1986, para entender como aplicá-lo à educação, à Teoria $U$ da sabedoria interna e, ainda, repensar, renovar e reengajar os conceitos, as posturas e os conhecimentos em busca do bem comum, da coletividade e da felicidade e transformá-los em ações políticas.

Aproveitamos, desta forma, para registrar algumas ideias do Seminário e o próprio encontro para consolidar a vocação da Pensar Verde em organizar conteúdos importantes e fomentar o debate qualificado por meio de disseminação de informações e pontos de vistas relevantes para a sociedade (PENSAR VERDE, 2015: 2).
}

Nascido dentro do processo de redemocratização brasileiro, o partido manifesta sua ideologia partidária, sua filosofia que o fundamenta, politicamente. Na estrutura narrativa deste discurso, o Percurso da Manipulação, de acordo com a terminologia semiótica, é o da instauração dos sujeitos, e o Percurso da Ação, é o da aquisição de competência e do desempenho de tais sujeitos. Em Sociossemiótica, numa análise da narrativa do discursos, considere-se que os sujeitos são coletivos. O Sujeito Destinador, a Política-Partidária, na ordem do saber, instaura um Sujeito Destinatário, o Sujeito que se identifica com o partido, manipulado por sedução, pois acredita, e passa a querer o Objeto de Valor, Mudança.

Segundo Greimas (2001), o ato de linguagem só é manifestado nos seus resultados e através deles, na qualidade de enunciado, enquanto a enunciação, que o produz, só possui o estatuto de pressuposição lógica, assim, em uma representação semântica é que se pode falar 
dele. A definição do ato como "o que faz ser" permite que se reconheça dois predicados: fazer x ser (enunciados de ação e enunciados de estado) que constituem uma narrativa mínima: 1) Estado - 2) Ação / Transformação - 3) Estado final.

Segundo a narratividade, portanto, uma ou várias transformações, cujos resultados são junções, conjunções ou disjunções dos sujeitos com os objetos de valor, bem como, sua modalização, num patamar mais profundo, destaca-se a estrutura polêmica de cada discurso manifestado nesse universo de propaganda político-partidária, sendo passíveis de análise, também, os anti-sujeitos, Anti-Destinador e Anti-Destinatário, respectivamente, por exemplo, Política-Econômica e Empresários.

Neste sentido e rumo à COP 21, esta edição tenta analisar política e objetivamente as metas brasileiras para o clima que serão apresentadas na grande conferência mundial de dezembro em Paris. É necessário reconhecer os avanços na postura do governo brasileiro, reconhecer os esforços dos verdes na exigência desses avanços para embasar o pedido de objetivos $e$ compromissos mais ousados sempre (Grifo nosso) (PENSAR VERDE 2015: 2).

Às portas da $21^{\mathrm{a}}$. conferência do Clima em Paris, após o desastre ambiental em Minas Gerais, o texto traz subjacente, um percurso gerativo do sentido contemporâneo sobre meio ambiente e sustentabilidade, que se trata de um discurso de uma sociedade de consumo, com hábitos altamente mutáveis (BAUMAN, 2008).

O discurso do poder-fazer-saber, para o poder-saber-querer, e para o poder-fazerdever(crer), é formador de vontade política e opinião. Nessa sociedade, o sentido do discurso de Pensar Verde (2015) apresenta uma narrativa em que se instaura um Sujeito que quer o Objeto de valor, um mundo melhor para todos. São discursos que insistem em destacar valores de preservação do meio ambiente e o desenvolvimento sustentável em contraposição à lógica do capital, cujos produtos midiáticos estimulam o hiperconsumo (MELO e BONINI, 2012).

A revista em questão, intitulada Pensar Verde, apresenta em toda sua estrutura de textos e artigos, sujeitos contrários, complementares e respectivos contraditórios, caracterizando, assim, o quadrado semiótico dos sujeitos nos discursos manifestados, que descreve a ação discursiva, por meio de uma lógica modal.

Ousadia não só na Conferência do Clima, mas também no protagonismo da nova Agenda 2030 das Nações Unidas, lançada pela Cúpula das Nações Unidas sobre o Desenvolvimento Sustentável em setembro, muito pouco divulgada pela imprensa brasileira e apresentada detalhadamente nesta edição. Acordada pelos 193 Estados-membros da ONU, a agenda proposta, intitulada "Transformando Nosso Mundo: a Agenda 2030 para o Desenvolvimento Sustentável”, consiste em uma Declaração com 17 Objetivos de Desenvolvimento Sustentável e 169 metas, meios de implementação e um mecanismo para avaliação e acompanhamento. A Agenda dá segmento e substitui os Objetivos do Milênio.

Para finalizar, conversamos com Paulo Saldiva, médico, professor universitário e SIGNOS DO CONSUMO, SÃO PAULO - V.7, N.2, 2015. P. 191-204, DEZ. 2015 
pesquisador, sobre como uma gestão verde das cidades é importante para reduzir a poluição e seus efeitos para a saúde do cidadão.

Boa leitura! (PENSAR VERDE, 2015: 2).

$\mathrm{Na}$ descrição dessa estrutura polêmica do discurso, em que se evidenciam as tensões em conflito, numa estrutura mais profunda, caracteriza-se, na Fig. 1, o quadrado semiótico dos sujeitos:

Fig. 1 - Quadrado Semiótico dos Sujeitos

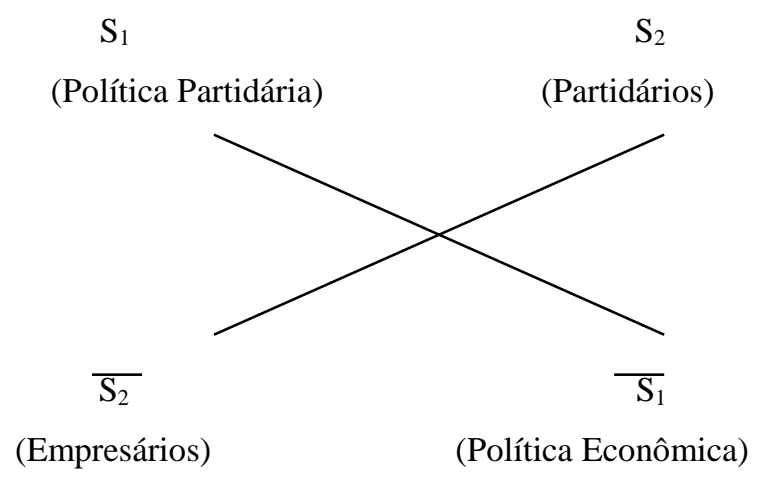

Na discursividade, também se manifestam os papéis actanciais que são revelados pelos atores, pois os planos, narrativo e discursivo, são correlatos numa relação de subordinação. Não são, porém, superpostos termo a termo, ou seja, um actante pode ser manifestado no discurso por vários atores, ou vice-versa. Por exemplo, um só ator pode ser o sincretismo de vários actantes, ou seja, pode ter vários papéis actanciais. O homem da sociedade contemporânea, que tem acesso ao conhecimento, aos problemas gerados nessa sociedade de consumo é um ator que pode desejar esse mundo sustentável, para a preservação do meio ambiente.

Explica-se, no patamar da semântica profunda, o modo de existência da significação como uma estrutura elementar, isto é, segundo Barros (1999: 77) como uma estrutura em que a rede de relações se reduz a uma única relação (oposição ou diferença) entre dois termos, no interior de um mesmo eixo semântico que os recobre. No entanto, para que dois termos possam ser apreendidos conjuntamente, é preciso que tenham algo em comum e é sobre esse traço comum que se estabelece uma diferença.

A ideologia da proteção ao meio ambiente está expressa na forma de publicação: uma plataforma online de conteúdo específico para publicações de acesso aberto, que reforça a proposta de equidade no acesso à informação e à conjugação do verbo: eu penso verde, tu pensas verde, ele pensa verde e assim por diante, endossando sua ideologia de proteção ao 
meio ambiente ao mesmo tempo que cria uma rede de sedução para o eleitor, convidando-o para a assunção do compromisso com a natureza e com os candidatos que serão lançados pelo partido.

\section{CONSIDERAÇÕES FINAIS}

Das remotas ações de grupos de jovens na década de 60, que já prenunciavam o cuidado com o planeta e foram mal recebidos pelo cenário neoliberal que despontava no pósguerra, um longo caminho transcorreu até a primeira conferência do clima ocorrida em Estocolmo em 1972. E, para o Brasil, só em 1985 que a redemocratização fez emergir partidos políticos que apontaram novos caminhos, novas ideologias no sentido de se criar discursos político-partidários pautados em mudanças sociais e ambientais, o que favorece a presença massiva de reflexões sobre as mudanças climáticas em 1992 com a conferência do clima no Rio de Janeiro.

Com a análise semiótica desses discursos, mais maduros no cenário político atual, é possível a reconstrução do discurso político, em que se manifestam valores expressos nas políticas públicas da contemporaneidade, no que se refere à sustentabilidade e meio ambiente. Por meio de um discurso político-partidário, manifestado no texto do editorial da Revista Pensar Verde, fica evidente que buscam reforçar seus valores, pela manipulação, na ordem do saber, pela sedução, caracterizada pela combinatória de modalidades do saber-fazer-querer, que caracteriza a vontade política.

Por meio dessa análise, pôde-se verificar que, no nível superficial do texto, a combinatória de processos significativos, ou unidades de significação, inscritas na linguagem de tal enunciado, produziu efeitos de sentido, que, por sua vez, conforme o contexto, possibilitou leituras e interpretações. E, concluindo a análise da estrutura narrativa e semântica profunda dos discursos, verifica-se que, por meio da descrição das etapas do percurso do sentido dos discursos foi possível detectar relações entre forças em jogo nos discursos, no âmbito da atual sociedade brasileira.

O estudo das estruturas dos discursos, segundo a Sociossemiótica, tornou possível a reconstrução do sentido e a definição das modalidades que caracterizam as estruturas de poder do discurso de propaganda político-partidário, manifestado no enunciado do texto analisado. É um discurso persuasivo que, segundo a metodologia semiótica, define-se por uma combinatória de modalidades do poder, o poder-fazer-saber (pode fazer alguém saber de algo), para o poder-fazer-querer (pode fazer alguém querer algo), para o poder-fazer- 
dever(crer), (pode fazer o dever e o crer), pois esse é um discurso político e é formador de vontade política e opinião.

\section{REFERÊNCIAS BIBLIOGRÁFICAS}

BARROS, D. L. P. Teoria Semiótica do Texto, São Paulo, Ática, 1999.

BAUDRILLARD, J. A sociedade de consumo, Lisboa, Edições 70, 1991.

BAUMAN, Z. Vida para o consumo. A transformação das pessoas em mercadoria. Rio de Janeiro, Jorge Zahar Ed., 2008.

PARTIDO VERDE. Revista Pensar Verde. Disponível em < http://issuu.com/pensarverde/docs/pensarverde15 > Acesso em 21 de dezembro de 2015.

CARREIRÃO, Y. S.; KINZO, M. D. G. "Partidos políticos, preferência partidária e decisão eleitoral no Brasil (1989/2002)", In Revista DADOS. Rio de Janeiro. Vol. 47. No.1. 2004: $131-168$

CHARAUdeAU, P.; MAInguenEAU, D. Dicionário de Análise do Discurso, $2^{\mathrm{a}}$ edição. São Paulo, Editora Contexto, 2008.

CHOMSKY, N. Controle da Mídia. Os espetaculares feitos da Propaganda, Rio de Janeiro, Graphia Editorial, 2003.

FOnTANille, J. Semiótica do Discurso. Trad. PORTELA, J. C., São Paulo, Contexto, 2008.

GREIMAS, A.J. e FONTANILlE, J. Semiótica das Paixões. Dos estados de coisas aos estados de alma, São Paulo, Ed. Ática, 1993.

GREIMAS, A. J. Del Sentido II. Ensaios semioticos. Madrid: Gredos, 2001.

LANDOWSKI, E. A Sociedade Refletida. São Paulo, EDUC editora da PUC, 1992. . Presenças do Outro, São Paulo, Perspectiva, 2002.

LOPES, E. Fundamentos da Linguística contemporânea, São Paulo, Cultrix, 1993.

MELO, E. M. \& BONINI, L. M.M. “Criatividade na cultura popular: Semiótica das políticas públicas de sustentabilidade", Revista Acta Semiótica et Linguística, Vol. 17, №. 2, 2012:80-89.

PAIS, C. T. Propaganda e Publicidade no interdiscurso. Os sujeitos dos discursos científico e tecnológico em busca de seus objetos de valor, In Revista Philologus, Ano 11, n 31, Rio de Janeiro, CIFEFIL, jan/abril, 2005. 
PRADOS, R. M. N. O discurso publicitário e a construção da Imagem dos Sujeitos nos discursos Político-eleitorais: um estudo à luz da Sociossemiótica. Relatório de Pesquisa de Pós-Doutorado em Ciências da Comunicação. Departamento de Relações Públicas, Propaganda e Turismo, Escola de Comunicação e Artes, ECA, USP. São Paulo: Universidade de São Paulo, USP, 2006.

_. Semiótica, discursos da mídia e cultura contemporânea. In: PRADOS, Rosália Maria Netto (org). Semiótica, Discursos e Cultura. São Paulo: Factash Editora, 2009: 53-62.

Artigo submetido: 14/08/2015

Artigo aprovado: 21/11/2015 